\title{
Anesthetic use in newborn infants: the urgent need for rigorous evaluation
}

\author{
Viviane G. Nasr ${ }^{1}$ and Jonathan M. Davis ${ }^{2}$
}

Approximately 1.5 million neonates receive general anesthesia each year for a surgical procedure. Despite this being an essential practice, a number of recent studies now indicate that anesthetic exposure could cause toxicity and neuronal apoptosis in the developing brain. This could potentially influence long-term neurodevelopmental outcome, especially premature infants in need of multiple surgical procedures. Most anesthetic drugs routinely administered to neonates have not been adequately tested for safety or efficacy. Given the number of confounders, dosing is often extrapolated from adults. This is concerning since many different drugs can be administered concurrently, with few of these agents actually approved for use by the Food and Drug Administration. Since 1997, legislation has been passed in the United States and abroad encouraging more drug investigation in infants and children. This has resulted in over 500 labeling changes to products regarding safety and efficacy in various pediatric age groups. However, only three drugs routinely used as anesthetic agents in newborn infants have had any updated labeling (none in very premature infants). This "off-label" use without adequate testing must be addressed. Therefore, more clinical trials of common anesthetic agents used alone and in combination in neonates are urgently needed.

\section{LEGISLATIVE MEASURES IN THE UNITED STATES AND EUROPE}

Recent legislative measures enacted in the United States and Europe are expanding the knowledge of drug use in infants and children by providing important incentives for conducting pediatric studies (Table 1) (1). Although the Best Pharmaceuticals for Children Act (BPCA) and the Pediatric Research Equity Act (PREA) updated more than 500 drug labels, only 12 involved anesthetic agents and none were studied in premature infants (2). The FDA Safety and Innovation Act (FDASIA, 2012) requires that the FDA obtain additional expertise in Neonatology to assist with all aspects of neonatal drug development, especially complex issues surrounding study design and outcome measures. In addition, FDASIA requires that written requests generated by the FDA under BPCA specifically include neonates. This approach discourages issuing waivers to companies reluctant to conduct studies in neonates due to concerns about safety or limited efficacy unless extremely compelling evidence exists (25\% of previous waivers were found after internal audits to have been issued in error) (3). Under PREA, pediatric study plans for qualifying drugs must now be submitted following the completion of phase II trials in adults after preliminary safety and efficacy data have been generated (4). Pediatric Regulations established in the European Union in 2007 had similar objectives to improve the health of children by facilitating the development and availability of medicines for children (5). Enhanced communication between the two regulatory agencies with respect to pediatric drug development now ensures that protocols being conducted in the United States and in Europe will be complementary in design given the more global scope of most pediatric product development.

\section{WHY HAVE SO FEW STUDIES BEEN CONDUCTED IN NEWBORN INFANTS (ESPECIALLY PRETERM INFANTS)?}

Over 500,000 premature infants are born annually in the United States and many require admission to a neonatal intensive care unit (NICU), costing $>\$ 26$ billion per year (6). Premature infants are at substantial risk of dying or developing serious morbidity that can affect them for life. Although considerable reductions in mortality and morbidity for premature infants occurred after the introduction of antenatal corticosteroids and surfactant $15-20$ y ago, significant improvements in outcome have not continued $(7,8)$. This highlights the challenges facing premature infants and indicates that novel approaches to significantly improve outcomes are urgently needed.

In this setting, most medications routinely used in the NICU lack convincing data to support their safety and efficacy and few new medications have been developed over the past two decades to substantially improve outcome. This is especially true for anesthetic agents used for surgical procedures in premature infants (9). There are actually significant disincentives to conducting research of anesthetic agents in preterm infants. Many Institutional Review Boards and the FDA are risk averse with this vulnerable population, with some even believing that it is unethical to conduct research in newborns $(10,11)$. Even studies conducted to better define standard of care (e.g., SUPPORT) have been challenged since many regulators are 


\section{Anesthesia in newborms $\mid$ Review}

unsure how these types of studies should be conducted (1214). Premature infants also represent a small market and may develop long-term disabilities which can be associated with significant liability, whether the adverse outcome is caused by the drug or not. There is no standard approach to anesthesia in premature infants with the decision to use a specific drug or drugs often based on the clinical impression of the anesthesiologist, an "expert opinion", or preliminary studies with the overwhelming majority of anesthetic drugs used in neonates not approved by the FDA. This is clearly an issue when the highest risk and most complex preterm infants need to be anesthetized for a surgical procedure.

\section{HOW DOES THIS APPLY TO ANESTHESIOLOGY?}

Anesthesiologists caring for neonates have to understand that most marketed drugs approved by the FDA are labeled only for use in adult patients. Withholding anesthesia from neonates who need surgery is impossible, so the use of one or more agents is often based on routine practice, experience, availability, and limited data. Between 1998 and 2003, the FDA issued written requests for the study of 242 drugs, with 53 studies actually conducted; 12 (23\%) were evaluated for safety only; 23 (43\%) for safety and efficacy and 18 (34\%) for pharmacokinetics and/or pharmacodynamics. However, only nine of these studies involved drugs used for anesthesia, pain and sedation and only two of these studies were published (15). Most importantly, only four of these studies involved infants less than one

Table 1. Legislative efforts to enhance drug development in children

\begin{tabular}{|c|c|c|}
\hline $\begin{array}{l}\text { Name of } \\
\text { legislation }\end{array}$ & $\begin{array}{l}\text { Year } \\
\text { passed }\end{array}$ & Major impact \\
\hline FDAMA & 1997 & $\begin{array}{l}\text { Six months market exclusivity (extra patent } \\
\text { protection) for conducting pediatric studies }\end{array}$ \\
\hline $\begin{array}{l}\text { Pediatric } \\
\text { Rule }\end{array}$ & 1998 & $\begin{array}{l}\text { Authorized FDA to require pediatric studies prior } \\
\text { to market authorization }\end{array}$ \\
\hline BPCA & 2002 & $\begin{array}{l}\text { Reauthorized provisions of FDAMA and allowed } \\
\text { FDA to request that NIH study off-patent drugs }\end{array}$ \\
\hline PREA & 2003 & Codified the Pediatric Rule \\
\hline FDASIA & 2012 & $\begin{array}{l}\text { Makes BPCA and PREA permanent; FDA must } \\
\text { obtain additional expertise in Neonatology }\end{array}$ \\
\hline $\begin{array}{l}\text { European } \\
\text { Union }\end{array}$ & 2007 & $\begin{array}{l}\text { Pediatric Investigation Plans needed for all new } \\
\text { drugs being developed; helped establish } \\
\text { Enpr-EMA }\end{array}$ \\
\hline
\end{tabular}

BPCA, Best Pharmaceuticals for Children Act; FDAMA, Food and Drug Administration Modernization Act; FDASIA, FDA Safety and Innovation Act; PREA, Pediatric Research Equity Act. year of age. Negative results are equally important as positive data since they may demonstrate safety concerns or lack of effectiveness, especially in younger age groups. This will also serve to notify other investigators that the study of a specific drug in a certain age range has been completed. Neonates are a vulnerable population and exposure to drugs should be limited as evidence for safety or toxicity is still lacking. In fact, extrapolation from adult data was proposed by the FDA in 1994; Dunne et al. (16) have shown that $61 \%$ of drugs studied using this approach received an indication in children when extrapolation was used. Under certain circumstances, this approach could potentially increase the number of drug approvals for pediatric use without requiring additional pediatric studies. It is clear that registering all clinical studies on clinicaltrials.gov should be mandatory and publishing all relevant data should be done irrespective of outcome (17).

\section{SPECIFIC ANESTHETIC AGENTS}

In anesthesiology, different classes of drugs and different combinations are used to provide amnesia, relaxation, and a painfree experience. From 2003 until the present, BPCA and PREA have facilitated the study of anesthetic-related drugs including propofol, ketamine, inhalational anesthetics (desflurane, sevoflurane, isoflurane), opioids (fentanyl, morphine, oxycodone, remifentanil), benzodiazepines (midazolam, lorazepam), muscle relaxants (rocuronium), $\alpha-2$ adrenoreceptor agonists (dexmedetomidine), and local anesthetics (lidocaine) in children (18). These efforts have included safety, efficacy, pharmacokinetic, and pharmacodynamic studies leading to updated labeling and safety information. For instance, there were a higher percentage of deaths reported with patients who received propofol compared with controls and more seizures occurred in children who received sevoflurane during surgery (18). However, only three of these studies involved neonates (e.g., rocuronium, remifentanil, sevoflurane) and none included premature infants, especially those born at 23-29 wk of gestation who are at the highest risk of death or neurodevelopmental impairment (Table 2) $(2,9,18,19)$.

Among the inhalational anesthetics, data mentioned on the drug labels indicate that it appears to be safe and effective to use sevoflurane in neonates as young as $9 \mathrm{~d}$ of age and desflurane in infants as young as $2 \mathrm{y}$ of age. However, recent data demonstrate a neurotoxic effect on the fetus and newborn in animals who have received some of these inhaled agents (20). Propofol can be administered for induction down to $3 \mathrm{y}$ of age and for maintenance down to 2 mo of age, but significant concerns exist

Table 2. Studies of anesthetic agents in neonates submitted to the FDA

\begin{tabular}{|c|c|c|c|c|c|c|}
\hline $\begin{array}{l}\text { Labeling date } \\
\text { change }\end{array}$ & Generic name & Indication & $\begin{array}{l}\text { Published } \\
\text { studies }\end{array}$ & \# Neonates & Major findings & $\begin{array}{c}\text { Reference } \\
\text { number }\end{array}$ \\
\hline 8 March 2004 & $\begin{array}{l}\text { Remifentanil } \\
\mathrm{HCl}\end{array}$ & $\begin{array}{l}\text { Maintenance of } \\
\text { anesthesia }\end{array}$ & One & 60 & $\begin{array}{l}\text { Similar recovery times, but less postoperative apnea in } \\
\text { infants receiving remefentanil compared to halothane }\end{array}$ & $(38,39)$ \\
\hline 28 August 2008 & $\begin{array}{l}\text { Rocuronium } \\
\text { bromide }\end{array}$ & $\begin{array}{l}\text { Adjunct to general } \\
\text { anesthesia }\end{array}$ & One & 28 & Not applicable & $(2,9)$ \\
\hline 30 March 2001 & Sevoflurane & General anesthesia & One & 180 & $\begin{array}{l}\text { Sevoflurane caused less episodes of hypotension than } \\
\text { halothane }\end{array}$ & $(40)$ \\
\hline
\end{tabular}




\section{Review | Nasr and Davis}

with using this agent in neonates $(2,19)$. Midazolam is a benzodiazepine that is routinely administered to neonates in the NICU, but does require modification of dosing in children with congenital heart disease and pulmonary hypertension (21). A recent Cochrane review found insufficient data to justify the routine use of midazolam in neonates and raised concerns about adverse neurologic outcomes (21). Based on the new pediatric drug-labeling database, the only muscle relaxant that has been studied in newborn infants is rocuronium, a nondepolarizing muscle relaxant $(2,9)$ Among the opioids, the efficacy and safety of remifentanil as an analgesic agent for use in the maintenance of general anesthesia has been examined in 21 premature infants at $29-32 \mathrm{wk}$ of gestation $(22,23)$. However, definitive safety of fentanyl has not been established in children younger than $16 \mathrm{y}$ of age which is concerning since this agent is routinely used for sedation and pain control in extremely premature infants in the NICU as well as routinely during surgery (2). A 2005 study showed an increased incidence of side effects including need for respiratory support and delay in achieving full enteral feedings with continuous fentanyl infusions compared to open-label boluses in very preterm infants receiving mechanical ventilation (24). Morphine, is a commonly used analgesic in preterm infants in NICU. While the use of this agent has been found to be associated with an increased risk of intraventricular hemorrhage and prolonged electrocortical depression on electroencephalogram, longerterm studies have not demonstrated any changes in the general function of children at 8-9 y and potential improvement in their executive functioning (25-27). Dexmedetomidine is a selective $\alpha-2$ adrenoreceptor agonist that produces sedation and has antinociceptive properties. A phase II/III multicenter study demonstrated the safety and efficacy of dexmedetomidine in sedating preterm and full-term neonates without significant adverse events (28). Safety and effectiveness of local anesthetics such as lidocaine (routinely used subcutaneously for invasive procedures or surgeries) has not been established in children less than $12 \mathrm{y}$ of age (18). These studies are particularly important since they provide evidence that pediatric dosing should not be determined by simply applying weight-based calculations to the adult dose. Drug clearance is highly variable in the pediatric population and is not readily predictable on the basis of adult information.

\section{ANESTHESIOLOGY INITIATIVES}

In addition to the relative lack of safety data, recent in vitro and in vivo studies have shown that the use of a variety of anesthetic agents in children less than three years of age (especially neonates and young infants) may cause neurotoxicity and possible long-term adverse neurodevelopmental outcomes as described in detail by Ramsay and Rappaport as well as Sun and associates $(29,30)$. In response to these concerns, the FDA's Anesthetic and Life Support Drugs Advisory Committee met in March 2007 and again in March 2011 concluding that there were insufficient data to warrant a change of practice. Subsequently, FDA entered into a public-private partnership with the International Anesthesia Research Society (IARS) called
SmartTots (Strategies for Mitigation of Anesthesia-Related Neurotoxicity in Tots) to mobilize the scientific community, stimulate dialogue among thought leaders in the anesthesia community, and work to generate funding for the necessary research studies. Two major prospective studies are ongoing in children: (i) The Pediatric Anesthesia Neurodevelopmental Assessment Study (PANDA) are comparing siblings less than $3 \mathrm{y}$ of age exposed to general anesthesia to those nonexposed; (ii) The GAS study is a multisite randomized controlled trial comparing neurodevelopmental outcomes in infants receiving general anesthesia compared to spinal and other regional anesthetics to control for the stress response to surgery (29). A recent retrospective cohort analysis of 12,111 preterm infants from the NICHD neonatal research network database demonstrated an independent association between infants undergoing a major surgical procedure and an increased risk of death or neurodevelopment impairment compared to infants having minor surgical procedures or no surgery (31). While the authors speculate that the effects of general anesthesia may have contributed to the abnormal outcomes, specific data on the types of anesthetic agents used (or combination of agents) was not available making it extremely difficult to establish a definitive association. While results of the GAS and PANDA studies are pending, Neonatologists, Pediatricians, Surgeons, and Anesthesiologists should be aware of potential neurotoxicity of anesthetics and sedatives (32). The use of spinal and regional anesthetics is definitely increasing for a variety of procedures where it can be safely employed.

\section{CHALLENGES TO CONDUCTING CLINICAL STUDIES IN NEONATES}

There are several unique limitations to conducting studies of anesthetic agents in neonates undergoing surgery since the use of anesthesia and analgesia is mandatory, the use of a placebo cannot be justified, and there are few comparative effectiveness studies demonstrating the benefit of a wide range of approaches (single or multiple systemic and/or inhaled agents) (33). In addition to difficulty in study design and choosing relevant outcome measures, obtaining parental consent for a research study of one or more anesthetic agents in a critically ill premature infant requiring a major surgical procedure may be challenging. The Anesthesiologist must address the risks and benefits as well as the degree of parental distress when surgery is required in a premature infant (34).

The evaluation of drug safety and efficacy requires a comprehensive assessment of the pharmacodynamics and pharmacokinetics of the drug. However, the continued maturation of different organ systems (especially the brain) as well as the developmental changes in receptor number and affinity throughout infancy can greatly influence the susceptibility of the premature infant to the effects of single or multiple anesthetic agents. There are multiple important age-related trends that must be analyzed including: (i) behavioral and autonomic responses to noxious stimuli, (ii) hepatic enzyme systems important for drug metabolism, (iii) Renal clearance of drugs and their metabolites, (iv) age-related differences in drug uptake and distribution, 


\section{Anesthesia in newborns $\quad$ Review}

(v) pharmacodynamic responses to medications, (vi) respiratory response to opioids, (vii) genetic polymorphisms in opioid receptors (OPMR1), transporters, and other enzyme systems that may significantly influence the response to different anesthetic agents, (viii) sensitivity of neurons to apoptotic or necrotic cell death following a variety of physiologic events or pharmacologic exposures, (ix) hemodynamic responses to general anesthesia, spinal anesthesia, and epidural anesthesia, (x) hormonal and metabolic responses to surgery and illness, and (xi) the strong possibility of drug-drug interactions since multiple agents are routinely administered in various combinations to the smallest and most critically ill preterm infants (35-37).

\section{CONCLUSION}

Our knowledge of the maturation of specific metabolic pathways is increasing, yet new and existing drugs are being administered to neonates each year without adequate safety profiles being identified and older drugs continue to be used in the absence of definitive safety and efficacy data. A process to address these deficiencies remains an urgent public health need. National legislation and funding opportunities are available to encourage clinical and basic research studying safety, potential toxicity, and effectiveness of drugs used routinely for anesthesia and analgesia in preterm and infants.

Recommendations for best practices for Pediatric Anesthesiologists or preferred clinical pathways for specific surgeries limiting the doses and exposure of single or multiple drugs is needed. In the interim, clinicians are advised to continue to tailor the care of neonates based on the patient's condition, to attempt to limit the exposure to multiple agents if possible, to consider alternative therapeutic approaches (e.g., spinal, local anesthetics) if viable, and to remain vigilant as new information is developed.

\section{ACKNOWLEDGMENTS}

The authors acknowledge and thank Robert "Skip" Nelson, MD PhD (Deputy Director and Senior Pediatric Ethicist, Office of Pediatric Therapeutics, Food and Drug Administration) for his input and advice. Dr. Davis is Chair of the Neonatal Advisory Committee, Office of Pediatric Therapeutics, FDA.

\section{STATEMENT OF FINANCIAL SUPPORT}

No financial assistance was received to support this study.

Disclosure: No financial disclosures.

\section{REFERENCES}

1. Hoppu K, Anabwani G, Garcia-Bournissen F, et al. The status of paediatric medicines initiatives around the world-What has happened and what has not? Eur J Clin Pharmacol 2012;68:1-10.

2. US Food and Drug Administration. New pediatric labeling information database, 2014. http://www.accessdata.fda.gov/scripts/sda/sdNavigation. $\mathrm{cfm}$ ?sd=labelingdatabase.

3. Rodriguez W, Selen A, Avant D, et al. Improving pediatric dosing through pediatric initiatives: what we have learned. Pediatrics 2008; 121:530-9.

4. US Food and Drug Administration. Pediatric study plan, 2013. http:// www.fda.gov/downloads/drugs/guidancecomplianceregulatoryinformation/guidances/ucm360507.pdf.

5. Turner MA, Catapano M, Hirschfeld S, Giaquinto C; Global Research in Paediatrics. Paediatric drug development: the impact of evolving regulations. Adv Drug Deliv Rev 2014;73:2-13.
6. Institute of Medicine of the National Academies. Preterm birth: causes, consequences, and prevention, 2006. http://www.iom.edu/Reports/2006/ Preterm-birth-Causes-Consequences-and-Prevention.aspx.

7. Shah PS, Sankaran K, Aziz K, et al.; Canadian Neonatal Network. Outcomes of preterm infants $<29$ weeks gestation over 10-year period in Canada: a cause for concern? J Perinatol 2012;32:132-8.

8. Horbar JD, Carpenter JH, Badger GJ, et al. Mortality and neonatal morbidity among infants 501 to 1500 grams from 2000 to 2009. Pediatrics 2012;129:1019-26.

9. Laughon MM, Avant D, Tripathi N, et al. Drug labeling and exposure in neonates. JAMA Pediatr 2014;168:130-6.

10. US Government Accountability Office. Pediatric Research: products studied under two related laws, but improved tracking needed by FDA, 2011. http://www.gao.gov/assets/320/319073.pdf.

11. Davis JM, Connor EM, Wood AJ. The need for rigorous evidence on medication use in preterm infants: is it time for a neonatal rule? JAMA 2012;308:1435-6.

12. Carlo WA, Finer NN, Walsh MC, et al. Target ranges of oxygen saturation in extremely preterm infants. N Engl J Med 2010;362:1959-69.

13. Finer NN, Carlo WA, Walsh MC, et al. Early CPAP versus surfactant in extremely preterm infants. N Engl J Med 2010;362:1970-9.

14. Hudson KL, Guttmacher AE, Collins FS. In support of SUPPORT-a view from the NIH. N Engl J Med 2013;368:2349-51.

15. Benjamin DK Jr, Smith PB, Murphy MD, et al. Peer-reviewed publication of clinical trials completed for pediatric exclusivity. JAMA 2006;296: 1266-73.

16. Dunne J, Rodriguez WJ, Murphy MD, et al. Extrapolation of adult data and other data in pediatric drug-development programs. Pediatrics 2011;128:e1242-9.

17. Benjamin DK Jr, Smith PB, Sun MJ, et al. Safety and transparency of pediatric drug trials. Arch Pediatr Adolesc Med 2009;163:1080-6.

18. Mellon RD, Simone AF, Rappaport BA. Use of anesthetic agents in neonates and young children. Anesth Analg 2007;104:509-20.

19. Roberts R, Rodriguez W, Murphy D, Crescenzi T. Pediatric drug labeling: improving the safety and efficacy of pediatric therapies. JAMA 2003;290:905-11.

20. Zheng H, Dong Y, Xu Z, et al. Sevoflurane anesthesia in pregnant mice induces neurotoxicity in fetal and offspring mice. Anesthesiology 2013;118:516-26.

21. Taddio A, Ohlsson A. Intravenous midazolam infusion for sedation of infants in the neonatal intensive care unit. Cochrane Data Syst Rev 2012;6:CD002052.

22. Welzing L, Roth B. Experience with remifentanil in neonates and infants. Drugs 2006;66:1339-50.

23. Welzing L, Kribs A, Huenseler C, Eifinger F, Mehler K, Roth B. Remifentanil for INSURE in preterm infants: a pilot study for evaluation of efficacy and safety aspects. Acta Paediatr 2009;98:1416-20.

24. Ancora G, Lago P, Garetti E, et al. Efficacy and safety of continuous infusion of fentanyl for pain control in preterm newborns on mechanical ventilation. J Pediatr 2013;163:645-51.e1.

25. Hall RW, Kronsberg SS, Barton BA, Kaiser JR, Anand KJ; NEOPAIN Trial Investigators Group. Morphine, hypotension, and adverse outcomes among preterm neonates: who's to blame? Secondary results from the NEOPAIN trial. Pediatrics 2005;115:1351-9.

26. Norman E, Wikström S, Rosén I, Fellman V, Hellström-Westas L. Premedication for intubation with morphine causes prolonged depression of electrocortical background activity in preterm infants. Pediatr Res 2013;73:87-94.

27. de Graaf J, van Lingen RA, Valkenburg AJ, et al. Does neonatal morphine use affect neuropsychological outcomes at 8 to 9 years of age? Pain 2013;154:449-58.

28. Chrysostomou C, Schulman SR, Herrera Castellanos M, et al. A phase II/ III, multicenter, safety, efficacy, and pharmacokinetic study of dexmedetomidine in preterm and term neonates. J Pediatr 2014;164:276-82.e1-3.

29. Ramsay JG, Rappaport BA. SmartTots: a multidisciplinary effort to determine anesthetic safety in young children. Anesth Analg 2011; 113:963-4. 
30. Sun L. Early childhood general anaesthesia exposure and neurocognitive development. Br J Anaesth 2010;105:Suppl 1:161-8.

31. Morriss FH Jr, Saha S, Bell EF, et al.; Eunice Kennedy Shriver National Institute of Child Health and Human Development Neonatal Research Network. Surgery and neurodevelopmental outcome of very low-birthweight infants. JAMA Pediatr 2014;168:746-54.

32. Williams R, Pfister R, Black I. The neonatologist's role in pediatric anesthesia neurotoxicity. JAMA Pediatr 2014;168:701-3.

33. Baer GR, Nelson RM; Ethics Group of the Newborn Drug Development Initiative. Ethical challenges in neonatal research: Summary report of the ethics group of the newborn drug development initiative. Clin Ther 2006;28:1399-407.

34. Hoehn KS, Nathan A, White LE, et al. Parental perception of time and decision-making in neonatal research. J Perinatol 2009;29:508-11.

35. Kasai S, Ikeda K. Pharmacogenomics of the human $\mu$-opioid receptor. Pharmacogenomics 2011;12:1305-20.
36. Anand KJ, Aranda JV, Berde CB, et al. Analgesia and anesthesia for neonates: study design and ethical issues. Clin Ther 2005;27:814-43.

37. Wachman EM, Hayes MJ, Brown MS, et al. Association of OPRM1 and COMT single-nucleotide polymorphisms with hospital length of stay and treatment of neonatal abstinence syndrome. JAMA 2013;309:1821-7.

38. Davis PJ, Galinkin J, McGowan FX, et al. A randomized multicenter study of remifentanil compared with halothane in neonates and infants undergoing pyloromyotomy. I. Emergence and recovery profiles. Anesth Analg 2001;93:1380-6, table of contents.

39. Galinkin JL, Davis PJ, McGowan FX, et al. A randomized multicenter study of remifentanil compared with halothane in neonates and infants undergoing pyloromyotomy. II. Perioperative breathing patterns in neonates and infants with pyloric stenosis. Anesth Analg 2001;93:1387-92, table of contents.

40. Russell IA, Miller Hance WC, Gregory G, et al. The safety and efficacy of sevoflurane anesthesia in infants and children with congenital heart disease. Anesth Analg 2001;92:1152-8. 